\title{
How estimated ant diversity is biased by the sampling method? A case study of Crete: a Mediterranean biodiversity hotspot
}

\author{
Sebastian Salata ${ }^{1,2,3}$ (D) Konrad Kalarus $^{2}$ (D) Lech Borowiec $^{3}$ (D) \\ Apostolos Trichas $^{4}$ (D) $\cdot$ Krzysztof Kujawa $^{2}$ (D)
}

Received: 11 September 2019/Revised: 29 June 2020 / Accepted: 3 July 2020 /

Published online: 14 July 2020

(C) The Author(s) 2020

\begin{abstract}
Defining biodiversity conservation goals requires representative and reliable data. However, data collected with the use of different methods can lead to divergent conclusions. Regardless of the high level of biodiversity of Mediterranean habitats, very little attention was paid in developing methods allowing rapid and scalable estimation of their richness. This study aims to recognize and explain the differences in performance of two methods: pitfall traps (PTM) and a complementary method based on hand collecting (HCM), in surveys of ants in the Mediterranean. We compared the results of applying both methods in three habitats in relation to $\alpha-, \beta$-, and $\gamma$-diversity, and functional traits of species, i.e. Webber's length (WL), nesting preferences, and evolutionary origin. Mean species number per HCM was significantly higher than per PTM sample. Spatial species turnover of HCM samples was higher than in PTM ones. However, assemblage dispersion did not differ. HCM detected a higher number of species and genera. WL differed significantly between HCM and PTM, and HCM recorded significantly more species in individual nesting guilds, regardless of considered habitat. HCM detected higher diversity of functional characteristic combinations of species. PTM detected fewer species with slightly larger body size and is useful in recognizing spatial species diversity patterns. HCM detected a higher number of species and produced more comprehensive results in identifying the functional diversity of ant assemblages. In conclusion, an integrated approach, described here as HCM, appears to be more suitable for heterogeneous Mediterranean habitats, especially when a survey aims at $\alpha-, \beta-$, and $\gamma$-diversity assessments.
\end{abstract}

Keywords Ants · Biodiversity hot-spot · Functional diversity · Island · Mediterranean · Species richness

Communicated by Andreas Schuldt.

Electronic supplementary material The online version of this article (https://doi.org/10.1007/s10531-02002014-5) contains supplementary material, which is available to authorized users.

Sebastian Salata

sdsalata@gmail.com

Extended author information available on the last page of the article 


\section{Introduction}

Recent studies revealed a severe decline in biodiversity (Spooner et al. 2018; SánchezBayo and Wyckhuys 2019; Soroye et al. 2020), highlighting an urgent need to develop survey methods that allow quick and comprehensive estimation of species diversity. An effective approach should facilitate locating places of special value for biodiversity and launching reliable conservation initiatives. Comprehensive biodiversity assessments have to be both time and cost effective, and be based on carefully selected groups of organisms (Fisher 1999). Popular taxa used as bioindicators include vascular plants, vertebrates, and some groups of insects, among which ants are a prominent group (Hölldobler and Wilson 1990).

However, estimations of ant diversity and community composition are impacted by applied sampling methodology (Agosti and Alonso 2000; Gotelli et al. 2011). The most common standardized methods used in ant-based inventories include pitfall traps, Winkler samples, and surface baiting (Agosti and Alonso 2000). There are also techniques used for sampling subterranean species (e.g., Pacheco and Vasconcelos 2012; Jacquemin et al. 2016). Nevertheless, the application of complementary techniques provides the most comprehensive picture of biodiversity and community composition (Agosti and Alonso 2000; Wong and Guérard 2017; Hanisch et al. 2018).

The majority of surveys focused on examining the efficiency of selected sampling methods in biodiversity surveys were conducted in tropical habitats (Donoso and Ramon 2009; Higgins and Lindgren 2012; Wiezik et al. 2015; Wong and Guénard 2017; Hanisch et al. 2018; Lee and Guénard 2019; Longino et al. 2019), since these habitats host the highest levels of terrestrial biodiversity around the globe. Less numerous reports come from the temperate zone (King and Porter 2005; Schlick-Steiner et al. 2006; Ellison et al. 2007; Lessard et al. 2007). Unfortunately, there is very limited data on the efficiency of sampling methods in assessments of the ant diversity of arid Mediterranean region (Abril and Gómez 2013), which is recognized as one of the global biodiversity hotspots (Cuttelod et al. 2009).

In this study, we compared the output of two methods, i.e. hand collecting (HCM) and pitfall trapping (PTM), for the inventory of Cretan ant assemblages. The HCM method is a complementary technique based predominantly on hand collecting, while PTM is a collecting method commonly used in inventories carried out in the Mediterranean. This study aims (1) to recognize differences between these methods in assessing biodiversity patterns and (2) to explain the differences in outcomes of these methods by recognizing distinctions in detected assemblages, and comparing how these methods "filter" the ant assemblages. To achieve the first goal, we compared the results of PTM and HCM, at the species- and genus-level, with reference to $\alpha$-, $\beta$-, $\gamma$-diversity. Additionally, we compared the outcomes of both methods in detecting endemic taxa. To achieve the second goal, we checked the impact of ant species' traits into assemblages recognized by a particular collecting method. We focused on two aspects of the differences i.e. when a single trait and multiple traits are considered. The analysis of the differences in performance of the methods used for biodiversity assessment of insects (including ants) based on functional species' traits has rarely been analyzed in previous studies.

Considering earlier publications (i.e. Gotelli et al. 2011), we expected a better performance of HCM in the detection of $\alpha$-diversity and spatial variation of assemblage species composition. Also, we anticipated that PTM would detect more ant species nesting in soil, while HCM would detect more species nesting on low vegetation and trees. 


\section{Materials and methods}

\section{Study area}

Crete, the largest Greek island, lies at the southernmost margins of the Aegean archipelago with an area of $8400 \mathrm{~km}^{2}$, being the fifth-largest island in the Mediterranean (Vogiatzakis et al. 2016). It has been called a "miniature continent", due to its long isolation history and the intense tectonic dynamics (Rackham and Moody 1996). The Cretan landscape is highly mountainous, defined by large and high mountain ranges crossing from west to east, three of them exceeding $2000 \mathrm{~m}$ of elevation. In general, aridity increases from west to east and from north to south. Annual precipitation ranges from about $240 \mathrm{~mm}$ in the south-east to at least $2000 \mathrm{~mm}$ in the high White Mountains range (Lefka Ori) (Grove and Rackham 1993). The temperature on mountains falls at a rate of about $6{ }^{\circ} \mathrm{C}$ per $1000 \mathrm{~m}$, on average (Rackham and Moody 1996). Above $1600 \mathrm{~m}$, most of the precipitation falls as the snow that covers the ground from late October until May (or even July, locally on Lefka Ori range).

Phrygana (sensu di Castri et al. 1981), maquis (Quercus coccifera mainly), intermediate mosaic formations of both, as well as subalpine shrubs, cover most of the Cretan landscape. Traditionally they are considered to be a result of woodland degradation due to grazing and burning (di Castri et al. 1981). Pine forests in Central and East Crete (Pinus brutia), Cypress forests in West Crete (Cupressus sempervirens), and patches of oak forests (Quercus ithaburensis \& ilex) are also found mainly on mountain cliffs. Lowland shrublands present at lower elevations may reach the alpine zones, confirming the weak zonation of vegetation on Crete (Vogiatzakis et al. 2016).

Crete, as most of the other Greek islands, has undergone intensive human influence (at least 8000 years, Legakis et al. 1993; Poulakakis et al. 2015). The present population of approximately 500,000 is mainly active in agriculture and tourism. In the last 20 years, the coast of the island (total length of $1046 \mathrm{~km}$ ) has received the heaviest brunt of human activity. The increases in tourism, industrialization, and urbanization have pushed people toward the coastal areas. Thus, today more than $50 \%$ of the island population lives within a distance of $5 \mathrm{~km}$ from the coast. Intensive grazing on the mountains of Crete, one of the oldest human activities on the island, is widespread and still profoundly shaping the Cretan landscape (Kaltsas et al. 2013).

Due to its complex geological history combined with mountainous relief and the geographical position, Crete is one of the most diverse and heterogeneous Mediterranean regions. The fragmentation of Crete, from the lower Tortonian (11 Mya) until the late Pliocene (2-3 Mya), may have resulted in allopatric speciation on these paleo-islets (Dermitzakis 1990; Douris et al. 1998; Welter-Schultes and Williams 1999; Fassoulas 2001). After the reunion of paleo-islands in Pliocene, the populations of the ancestral species of the radiations that became previously isolated may have evolved into separate species (Hausdorf and Sauer 2009). However, recent data shows that the island biodiversity is adversely affected by climate changes and human activity (Vogiatzakis et al. 2016). Regardless of the richness and distinctiveness of its organisms, the majority of Cretan terrestrial invertebrates remain understudied. Additionally, most often the assessment of species richness is limited by the lack of appropriate taxonomic expertise and difficulties in determination to the species level. However, recent surveys reported a high diversity of studied invertebrates (e.g. Schmalfuss et al. 2004; Simaiakis et al. 2004; Bosmans et al. 2013; Salata et al. 2018), including a high number of endemic species (Sfenthourakis and 
Legakis 2001), representing up to $50 \%$ of some groups (Triantis and Mylonas 2009). One of the biggest challenges in using ants as bioindicators are difficulties in the determination of material to species-level (Abril and Gómez 2013). Recent taxonomic work by the authors (Borowiec and Salata 2014; Salata and Borowiec 2015, 2017, 2019; Salata et al. $2018,2020)$ provide the necessary framework to identify the ants of Crete.

\section{Ant datasets}

In our study, we analyzed material (76 samples) deposited in the Natural History Museum of Crete, collected with pitfall trap method (PTM) in the last decades, and material (178 samples) housed in the Department of Biodiversity and Evolutionary Taxonomy, Wrocław, Poland, gathered with the use of the complementary method (HCM). We consider as "sample" all ant specimens collected in one study site (that is 76 and 178 study sites for PTM and HCM, respectively). In both cases, the study sites were distributed on the whole island, at elevations from 0 to $2131 \mathrm{~m}$. Medians for the elevation of PTM and HCM study sites amounted to $425 \mathrm{~m}$ and $318 \mathrm{~m}$, respectively, and the difference was statistically insignificant (Mann-Whitney's test: $\mathrm{U}=5796.5, \mathrm{P}=0.071$ ).

The study sites were located in three land cover classes: woodland, open habitats, and disturbed habitats based on a 1-km resolution grid cell. The percentage of given land-use type cover in a grid cell was calculated based on the sum of the coverage of land cover data of 1-km resolution obtained from the EarthEnv database (www.earthenv.org/landcover, Tuanmu and Jetz 2014). The category 'Woodland' includes: evergreen/deciduous or needle leaf trees, evergreen broadleaf trees, deciduous broadleaf trees, mixed/other trees; the category "Open" comprises shrubs or herbaceous vegetation, and the category 'Disturbed' covers cultivated and managed vegetation and urban or built-up area. Each grid was assigned to the class with the highest percentage of cover. The proportion of recognized three land cover categories did not differ between the collecting methods. The share of 'Woodland', 'Open', and 'Disturbed' amounted to 13, 55, and 31\% in PTM. In HCM, it reached 11, 53, and 35\%, respectively. The difference between PTM and HCM was statistically insignificant in Chi-square test: $\chi_{2,254}^{2}=0.42, \mathrm{P}=0.81$.

\section{Pitfall trap sampling (PTM)}

The PTM was used in the years 1988-2013, usually in 8-10 sites per year. As many as 15 traps $(9.5 \mathrm{~cm}$ trap diameter, and $12 \mathrm{~cm}$ depth) per site were distributed in straight line placements in homogenous vegetation patch, only avoiding the proximity of visible ants' nests. A minimum distance of $8 \mathrm{~m}$ between traps was kept, and usually, covered more than $150 \mathrm{~m}$ (in straight line placements) of habitat. The traps were filled up with ethylene glycol or undiluted propylene glycol as a killing/preserving agent (Trichas et al. 2008; Kaltsas et al. 2013). Occasionally, a small quantity of attractants like vinegar, or surface tension reducers like liquid soap, were used. Large stones to prevent/minimize both flooding and damage from grazing animals (exclusively sheep and goat flocks on Crete) were always placed above the plastic traps. The estimated time invested in settling, collecting, sorting, and evaluating a single sample is $2.5 \mathrm{~h}$. The traps were sampled bi-monthly (as described in Kaltsas and Simaiakis 2012). They were active year-round; however, in several study sites, there was an overlap of the first two months in the next year. Thus, the traps were active 14 months in total. Hence, the samples were collected six or seven times per 12 or 14 months, except at elevations above $1500 \mathrm{~m}$ on the mountains, which were covered by 
snow from November till late April. These sampling stations were inactive for that period and usually produced three samples per year.

\section{Hand collecting (HCM)}

The material was collected by Sebastian Salata (SS) or Lech Borowiec (LB) in May 2011 (LB), May 2013 (LB and SS) and April-May 2014 (SS) on transects of up to $200 \mathrm{~m}$ of length and $3 \mathrm{~m}$ width, and located in homogenous habitat patches. Specimens were collected with the use of the following techniques: (a) direct hand collecting of observed individuals, (b) nest finding, (c) soil sampling, (d) entomological umbrella, (e) litter sampling. The collecting period was estimated at approximately $1 \mathrm{~h}$ per transect and, to avoid heat peaks and low ant activity, was performed between 9 am-12 and 3-6 pm. The first stage involved collecting specimens from nests on the ground, in leaf litter and rock rubble, stones and tree trunks. In localities lacking litter or soil, rocks and stones were split with the use of a chisel. Nests were searched by lifting moderate-size rocks and tree barks, and splitting nuts, empty grass stalks, and shrub twigs. Nest series were collected in separate, labeled vials. Afterward, specimens foraging on the soil, rocks, and leaf litter were collected into vials. In the localities with a well-developed soil layer, we dug $20 \mathrm{~cm}$ deep holes to search for small and cryptic species. The distance between holes was estimated at $10 \mathrm{~m}$. At first, we watched for approximately 3 min and searched sides of dug holes to locate specimens hidden between soil grains. Afterward, the lifted chop of soil was placed on a white sheet for $2 \mathrm{~min}$ and later searched for ant specimens. The material from bushes and shrubs was collected with the use of an entomological umbrella. The umbrella was placed below low vegetation, and specimens were collected for $10 \mathrm{~s}$ by shaking vegetation with approximately $1 \mathrm{~m}$ long, wooden stick. The procedure was repeated every $10 \mathrm{~m}$ along the transect. In woodlands, material collecting was supplemented by litter sifting. Around $20 \mathrm{~cm}^{2}$ of leaf litter was collected from the ground and sieved into a sifter with $1 \times 1 \mathrm{~cm}$ wire mesh. Sieved material was placed on a white sheet, and specimens were collected for $2 \mathrm{~min}$. The procedure was repeated every $10 \mathrm{~m}$ along the transect. All specimens were preserved in $75 \% \mathrm{EtOH}$.

\section{Functional characteristics of ant species}

To recognize how the use of PTM and HCM "filters" the ant species from the assemblage by its functional traits, we considered the three following features: the Weber's length, nesting preferences and species zoogeographic affiliation. Weber's length is the diagonal length of the mesosoma in profile view and correlates with metabolic characteristics of ants (Parr et al. 2017). According to nesting preferences, species were classified in four nest guilds: nesting obligatory in soil (Soil); nesting in debris, litter or low vegetation (Deb); nesting above ground level (trees and rocks) (Veg); and nesting in various places (Var). The third classification was based on zoogeography, and the species were divided into three groups: endemic (E), introduced (I), and native (N). This division is not based on species traits directly. However, usually, these species groups are characterized by underlying different ecological features (e.g. introduced species are more flexible than native and endemic ones, or endemic taxa have narrower ecological niches that native ones). The pattern of the ecological group share in collected material did not differ between wood, open, and disturbed habitats (Fig. 1). 


\section{Statistical analysis}

\section{Differences between PTM and HCM in assessing $\alpha, \beta$, and $\gamma$-biodiversity}

To check whether $\alpha$-diversity differs between the compared methods, we performed a generalized linear model (hereinafter referred to as GLZ) with negative binomial error distribution for the number of species and the number of endemic species as dependent variables.

The effect of the method on $\beta$-diversity was analyzed in relation to two aspects: (1) spatial species (or genus) turnover, and (2) assemblage dispersion, considered here as a variation in species (or genus) composition within groups of samples (for HCM and PTM, separately). Analyses, based on presence-absence data, were done with the use of the Raup-Crick distance as a dissimilarity measure (Vellend et al. 2007). We used Bray-Curtis distance to analyze quantitative data (e.g., number of species belonging to the particular genus) (Kindt and Coe 2005).

To describe the patterns of spatial turnover of species and genera, we conducted the nonmetric multidimensional scaling (NMDS) with ten random initial configurations. The purpose of NMDS is to merge information from multiple dimensions (e.g., from multispecies assemblages) and facilitate their presentation and interpretation. The NMDS method uses rank orders and allows to accommodate and compare a variety of different types of data (Kindt and Coe 2005). Final matching values (so-called 'stress') reached $0.137,0.120$, and 0.087 and were calculated for four dimensions of the dissimilarity space, automatically defined by the software. It is usually considered that stress values below 0.2 reflect the good reliability of analyses (Clarke 1993). Differences in the species composition of ant assemblages between the collecting methods were tested using ANOSIM analysis (Hammer et al. 2001). The species with the highest impact on the differences in species assemblages between the sampling methods were recognized with the use of SIMPER analysis (Hammer et al. 2001).

The other component of $\beta$-diversity, compared between PTM and HCM, was the assemblage dispersion that can be considered as analogous to the homogeneity of variance
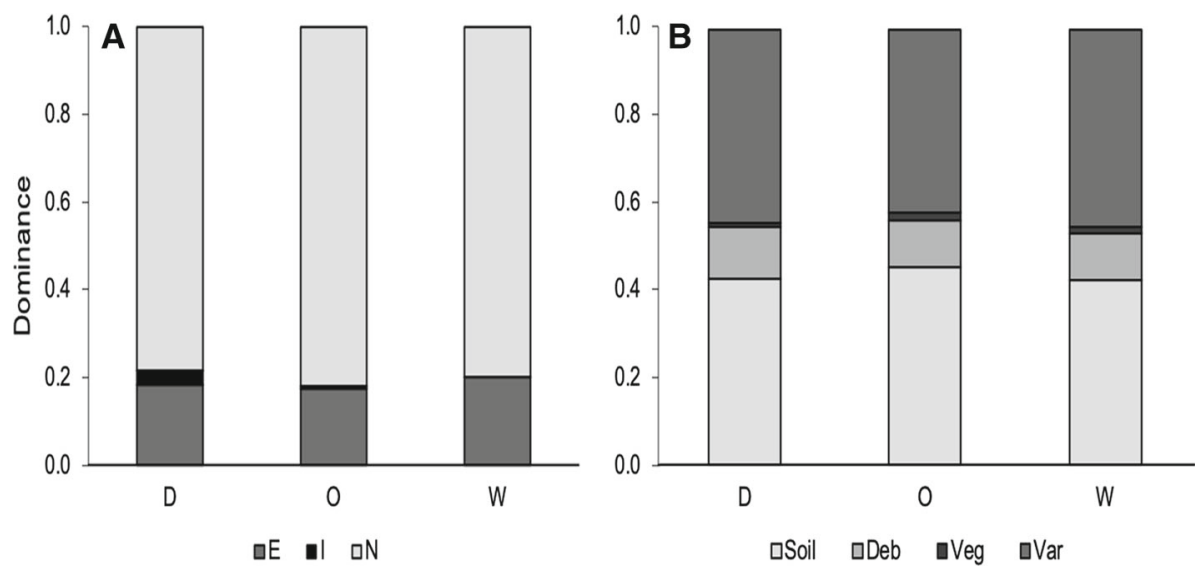

Fig. 1 The dominance of ecological groups in ant assemblages in relation to land cover types with the use of two classifications of species: evolutionary origin (a), and preference for nesting sites (b). Habitats: $D$ disturbed, $O$ open, $W$ woodland; ant species: $E$ endemic, $I$ introduced 
(Anderson 2006). It assumes that the composition of assemblages can vary within a given set of environmental conditions. In our case, both HCM and PTM study sites were distributed across the whole island, covering its main habitat types (Fig. 2). Thus, the assemblage dispersion can be considered here for a spectrum of environmental conditions that are representative of the island. Datasets of assemblage dispersion (separately for PTM and HCM) consisted of the distances of each sample from a centroid calculated in the principal coordinate space (Anderson and Ellingsen 2006). Pairwise permutational F-tests, analogous to Levene's test to compare variance homogeneity, with 999 permutations were applied for species and genus assemblages to find out if multivariate dispersion was alike across the collecting methods (Anderson 2006).

To compare the performance of PTM and HCM in assessing $\gamma$-diversity, we ran Mao's tau sample rarefaction procedure (Colwell et al. 2004) to generate species, genus, and endemic species accumulation curves (sample-based one). We also used the Chao2 estimator with bias correction (Chao 1987; Colwell 2009) to estimate species richness separately for both sampling methods.

\section{Differences between PTM and HCM in relation to ant species traits}

We used PERMANOVA (Hammer et al. 2001) to test whether sampling methods have a significant effect on functional diversity characteristics i.e., on the number of species that belongs to functional groups, recognized based on nesting preferences (applying BrayCurtis distance), and values of calculated functional diversity indices, i.e. FRic, FEve and FDis [applying Euclidean distance, which is more appropriate for standardized data (Kindt and Coe 2005)]. The Weber's length was compared between HCM and PTM with the use of General Linear Method, considering the effects of Habitat (Woodland, Open, Disturbed) and Methods (HCM, PTM) and interaction Habitat $\mathrm{x}$ Method. To describe the functional diversity of ants, we carried out a principal component analysis (PCA), a linear unconstrained ordination method. If the results of PERMANOVA were significant, we supported them with the PCA diagrams. For functional diversity indices, because PCA is sensitive to numerical values of different unit levels and may lead to incorrect results (Kindt and Coe 2005), we standardized the variables by dividing values of each sample by means of values from all the samples. Considering all three classifications of ant functional groups (Webber's length, nesting preferences, and evolutionary origin), based on the Gower
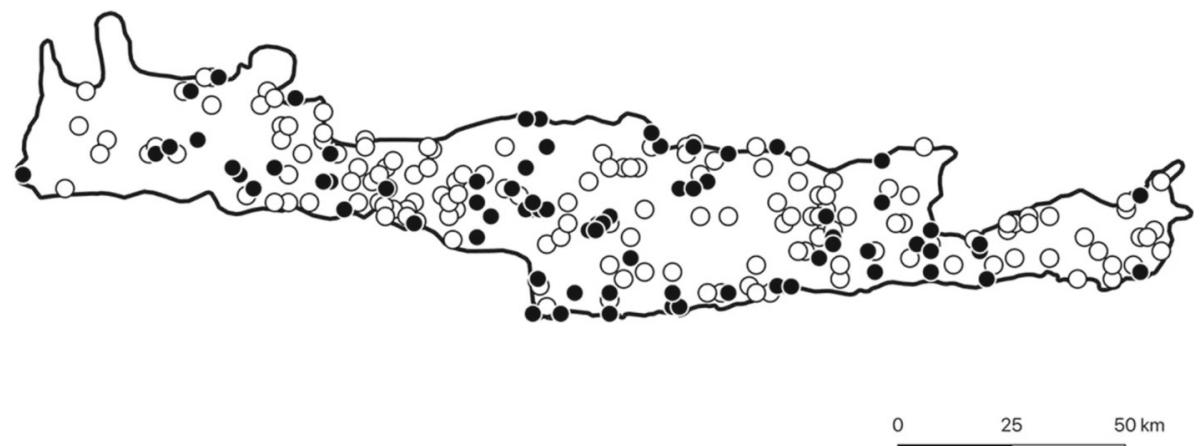

Fig. 2 Location of the study sites on Crete. Black circles—samples collected with PTM, white circlessamples collected with HCM 
dissimilarity (Gower 1971), we calculated the following indices of functional diversity: functional richness (FRic), which is measured as the convex full volume representing the functional/niche space occupied by the assemblage; functional evenness (FEve), which is based on the minimum spanning tree which links all the species in the multidimensional functional space and reflects the regularity in which species are distributed along the tree (Villéger et al. 2008); functional dispersion (FDis), analogous to assemblage dispersion index, which is measured on the PCoA space as the mean distance in multidimensional trait space of individual species to the centroid of all species (Laliberté and Legendre 2010); Rao's quadratic entropy (RaoQ), conceptually similar to FDis, which measures the pairwise functional differences between species and has zero value when all species are functionally equivalent (Botta-Dukát 2005).

Using Bailey's availability tests (Bailey 1980), based on classification of ants nesting preferences, we tested for three habitats i.e., Open, Woodland, and Disturbed whether a given sampling method underestimates or overestimates the ant functional groups i.e., how the share of the particular functional group is over- or understated. The pool (availability) of the groups was calculated separately for each habitat type, using all observations of ant species obtained for both sampling methods in the particular type of habitat. The proportions of ant observations in particular functional groups for sampling methods were compared with ant species poll (their availability).

\section{Statistical software}

The rarefaction procedure, Chao2 index, SIMPER, and PERMANOVA analyses were run in PAST 3.01 (Hammer et al. 2001). The GLZ modeling, ANOSIM, assemblage dispersion analysis, and functional diversity indices calculation were performed in R 3.4.3 software and packages Stats, Vegan, and FD (R Core Team 2018). The NMDS and PCA ordinations were carried out with Canoco for Windows 4.5 (Lepš and Šmilauer 2003).

\section{Results}

In total, 90 ant species were recorded, of which 87 were collected by HCM (40 exclusively by this method) and 50 were sampled by PTM ( 3 exclusively by this method). The number of species per sample amounted to 1-28 for HCM, and 1-19 for PTM.

Fig. 3 Alpha-diversity indicesmeans with $95 \%$ confidence intervals for observed numbers of all ant species and number of endemic ant species on study sites obtained with the use of HCM (circles) and PTM (triangles)

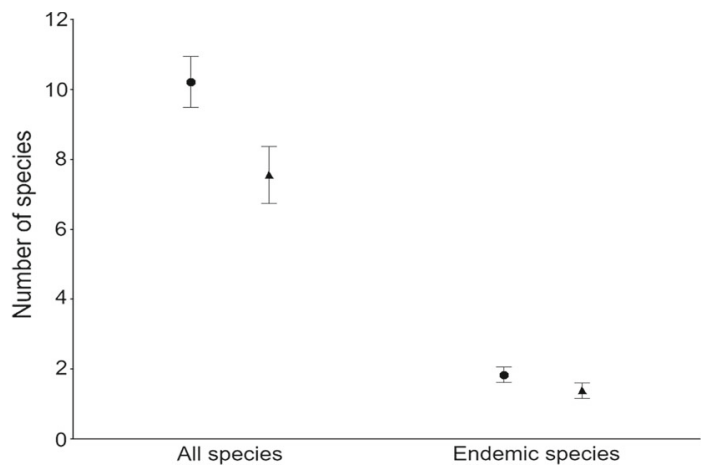


Fig. 4 Ordination diagrams of the NMDS analysis representing a spectrum of ant assemblages recorded with the two sampling methods-HCM and PTM, based on: presence-absence data representing species composition of assemblages (a), presenceabsence data representing genus composition of assemblages (b), the number of species belonging to particular ant genus (analogously to species composition with the species abundances)
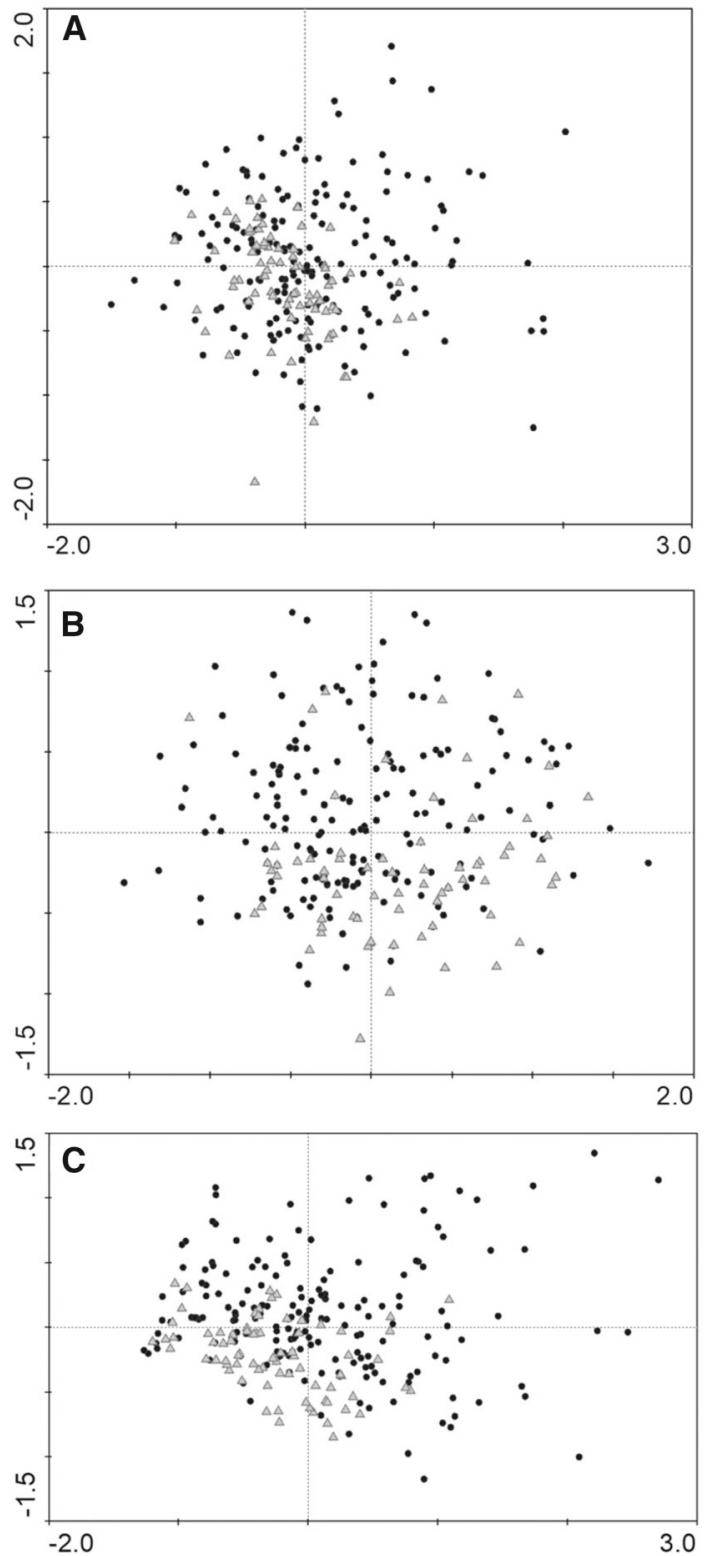

\section{Differences between PTM and HCM in assessing $\alpha, \beta$, and $\gamma$-biodiversity}

The mean number of species per sample ( $\alpha$-diversity) assessed with the use of HCM amounted to 10.2 and was higher than PTM by approximately $35 \%$ (Fig. 3). The difference was statistically significant (GLZ: $\left.\mathrm{Z}_{1,252}=4.452, \mathrm{P}<0.001\right)$. The mean number of endemic species per site in HCM and PTM data amounted to 1.2 and 0.8 , respectively (Fig. 3), and the difference was statistically significant (GLZ: $\left.Z_{1,252}=2.711, P=0.007\right)$. 
Table 1 Results of Simper analysis

\begin{tabular}{llll}
\hline & Contrib. (\%) & Cumulative (\%) & Dissimilarity \\
\hline Camponotus baldaccii & 4.3 & 4.3 & 3.2 \\
Pheidole pallidula & 4.3 & 8.6 & 3.2 \\
Messor wasmanni & 4.3 & 12.9 & 3.2 \\
Crematogaster sordidula & 4.3 & 17.2 & 3.2 \\
Lepisiota nigra & 4.3 & 21.5 & 3.2 \\
Aphaenogaster simonellii & 4.2 & 25.7 & 3.1 \\
Monomorium creticum & 3.7 & 29.4 & 2.7 \\
Camponotus kiesenwetteri & 3.6 & 33.0 & 2.6 \\
Camponotus gestroi & 3.5 & 36.5 & 2.6 \\
Camponotus aethiops & 3.4 & 39.9 & 2.5 \\
Plagiolepis pygmaea & 3.4 & 43.3 & 2.5 \\
Crematogaster ionia & 3.1 & 46.4 & 2.3 \\
Camponotus candiotes & 3.0 & 49.4 & 2.2 \\
\hline
\end{tabular}

Table shows ant species up to the cumulative 50\% average dissimilarity between species assemblages detected by HCM and PTM

Spatial species turnover, one of the two analyzed components of $\beta$-diversity, differed between PTM and HCM as reflected by statistically significant ANOSIM's statistics for species and genus composition (Raup-Crick distance, $\mathrm{R}=0.060, \mathrm{P}=0.019$, and $\mathrm{R}=0.096, \mathrm{P}=0.003$, respectively), as well as for the number of species belonging to the particular genus (Bray-Curtis distance, $\mathrm{R}=0.080, \mathrm{P}=0.006$ ). Furthermore, in terms of the above-mentioned features, the assemblages distinguished by HCM were more diversified than those recognized by PTM. It is expressed by the larger dispersion of HCM points in the ordination diagram (Fig. 4), which shows that dissimilarities between assemblages recognized by HCM were bigger than the PTM ones. Based on the SIMPER analysis, 13 species were primarily responsible for the differences (up to cumulative $50 \%$ of dissimilarity) observed between the assemblages detected with the use of PTM and HCM (Table 1). All the species were endemic or native.

In assemblage dispersion (second components of $\beta$-diversity), we detected no significant differences between the collecting methods for both ant species (Raup-Crick distance, pseudo- $\mathrm{F}_{1,252}=0.518 ; \mathrm{P}=0.490$ ) and ant genera (Raup-Crick distance, pseudo$\left.F_{1,252}=1.270 ; P=0.264\right)$. Therefore, the ant assemblages had the same level of similarity variation regardless of the used method (Fig. 5).

Rarefaction curves revealed that HCM detected a higher number of ant species and genera ( $\gamma$-diversity indices) than PTM did, regardless of the number of samples (Fig. 6). Chao2 index was higher for data from HCM for both, species number (HCM: $116 \pm 17.8$ SE; PTM: $59 \pm 7.3$ SE) and the number of genera (HCM: $29 \pm 3.1$ SE; PTM: $18 \pm 1.3$ ).

\section{Differences between PTM and HCM in relation to functional characteristics of ant species}

The mean ant body size (Webber's length) in PTM and HCM samples amounted to $1.6 \pm 0.1 \mathrm{~mm}$, and $1.5 \pm 0.0 \mathrm{~mm}$, respectively. The difference (for logarithmized values) 


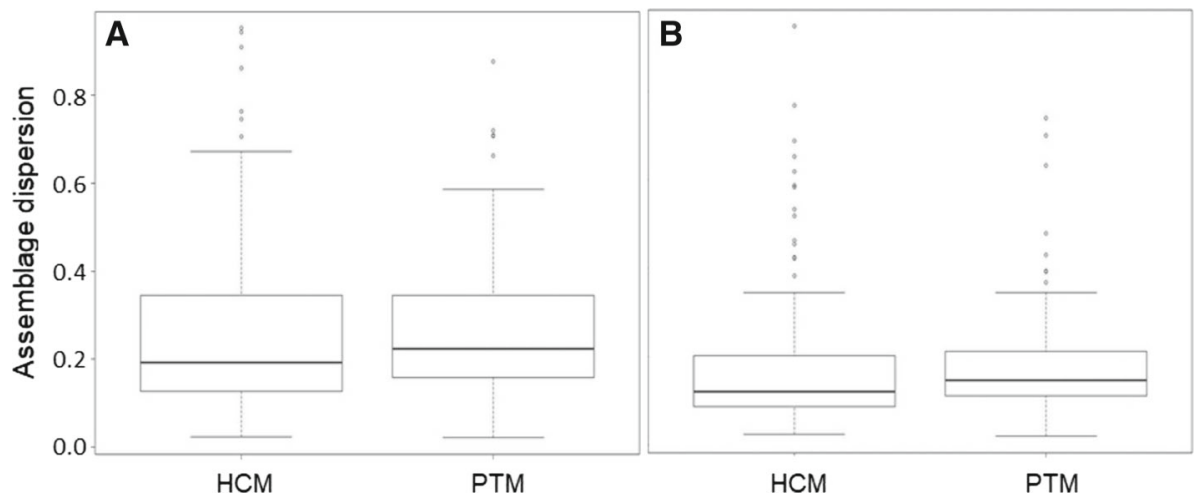

Fig. 5 Boxplots of assemblage dispersion measured with Raup-Crick distances for ant species (a) and ant genera (b) for HCM datasets and PTM datasets

was statistically significant $\left(\mathrm{F}_{1,254}=7.75, \mathrm{P}=0.005\right)$, while the interaction between Habitat and Method, and effect of Habitat were not $\left(\mathrm{F}_{2,254}=0.08, \mathrm{P}=0.92\right.$, and $\mathrm{F}_{2,254}=2.47, \mathrm{P}=0.09$, respectively). $\mathrm{HCM}$ recorded significantly more species in all the three nesting guilds, and no interaction with the habitat type was statistically significant (Table 2).

The composition of assemblages recognized based on nesting preferences did not differ between methods (Bray-Curtis distance, $\mathrm{F}=1.436 ; \mathrm{P}=0.225$ ) (Table S1). Thus, despite the fact that PTM generally detected a lower number of species, the share of a particular ant group in all assemblages was similar. Bailey test confirmed that this pattern was also independent of all investigated habitat types (Fig. 7). The great majority of functional groups were detected with the same effectiveness by both sampling methods in all three habitat types. Only one exception was recorded in a disturbed habitat, where the group of species nesting in the litter and on low vegetation was underestimated by PTM (Fig. 7). $\mathrm{HCM}$ recovered ant assemblages with higher functional diversity when multiple functional traits of species were considered (Euclidean distance, $\mathrm{F}=3.746 ; \mathrm{P}=0.0321$ ) (Fig. 8). Ant assemblages were characterized by higher FRic, as well as slightly higher FDis and RaoQ, while the FEve had a similar value in the assemblages detected for HCM and PTM (Fig. 8, Table S1). Simultaneously, HCM detected a higher variation of assemblages characterized by functional diversity indices when the FRic and FDis values were large (Fig. 8, Table S1).

\section{Discussion}

Our results show that species richness varies with the sampling method, as found in similar studies (Fisher 1999; Ellison et al. 2007; Lopes and Vasconcelos 2008; Gotelli et al. 2011). As seen by Abril and Gómez (2013), HCM was a more suitable method for assessing ant species richness in the Mediterranean habitats. The number of sampled species and genera were higher with HCM than with PTM, regardless of the number of samples considered. Also, the species richness curve for HCM was closer to an asymptote. Despite substantial sampling efforts, rarefaction curves revealed that none of these methods could detect the entire Cretan ant fauna. 


\section{PTM and HCM in assessing biodiversity}

Overall, among the 100 taxa known from Crete, HCM sampled 87\% of them, while PTM sampled $50 \%$ of the species. Among the species recorded exclusively by the HCM method (Table S2) were the social parasites (Strongylognathus sp., Temnothorax muellerianus), arboreal species (e.g., Camponotus rebbecae), species nesting close to water resources (Hypoponera sp., Cryptopone sp.), in rock crevices (e.g. Aphaenogaster cecconii) and in rock rubble (e.g., Temnothorax exilis, Tetramorium kephalosi, Trichomyrmex perplexus). Similarly, some nocturnal and cryptic taxa (e.g., Aphaenogaster kervillei, Stenamma debile) and hypogaeic species (e.g., Lasius myops) were collected only with PTM. Also, as anthropogenic environments are most often not suitable for pitfall traps, PTM failed to detect some invasive species (e.g., Nylanderia jaegerskioeldi, Linepithema humile and Monomorium bicolor).

The comparison of the outputs in detecting the endemic species reveals additional differences. HCM detected $95 \%$ of known endemic taxa, while PTM reported only $28 \%$ of them. PTM recorded only endemic species nesting in the soil or associated with wooded grounds or pastures (e.g., Aphaenogaster rugosoferruginea, Cataglyphis cretica, Monomorium creticum). Moreover, PTM did not reveal some common endemics occurring in caves (Aphaenogaster cecconii) and rocky areas (e.g., Messor concolor, Oxyopomyrmex leavibus). Probably due to the fact that it is practically impossible or excessively laborious to dig traps in such terrains (Romero and Jaffe 1989; Gotelli et al. 2011; Sheikh et al. 2018). However, both methods failed in detecting Aphaenogaster balcanicoides, so far known only from its type specimens collected in the vicinity of Kalyves, a popular tourist resort on the island. The performance of HCM in detecting endemic species was reflected in the high number of endemic species (12) among taxa collected exclusively by HCM (38) (Table S2). Most of them are representatives of the genus Temnothorax. Lack of those species in pitfall traps can be explained by their foraging behavior, as workers usually limit themselves to the area surrounding the nests. Thus, since the pitfall traps for this study were purposefully placed as to avoid visible nests entrances, the probability of collecting this species would be low (c.f. Schlick-Steiner et al. 2006). Other endemic taxa collected

Table 2 Statistical significance (in GLZ) of method (HCM vs. PTM) and interaction of method with habitat on the number of species per sample in ant nesting guilds (Soil, Deb, Var) in relation to habitat types (Disturbed, Open, Woodland)

\begin{tabular}{|c|c|c|c|c|c|c|c|c|c|}
\hline \multirow[t]{2}{*}{ Nest } & \multirow[t]{2}{*}{ Habitat } & \multicolumn{3}{|c|}{$\mathrm{HCM}$} & \multicolumn{3}{|c|}{ PTM } & \multicolumn{2}{|c|}{ Effect significance $(\mathrm{P})$} \\
\hline & & $\mathrm{N}$ & Mean & $95 \% \mathrm{CI}$ & $\mathrm{N}$ & Mean & $95 \% \mathrm{CI}$ & Method & Method $\times$ habitat \\
\hline \multirow[t]{4}{*}{ Soil } & Disturbed & 63 & 3.95 & $(3.36 ; 4.55)$ & 24 & 3.13 & $(2.47 ; 3.78)$ & \multirow[t]{4}{*}{0.002} & \multirow[t]{4}{*}{0.700} \\
\hline & Open & 95 & 4.64 & $(4.12 ; 5.16)$ & 42 & 3.81 & $(3.23 ; 4.39)$ & & \\
\hline & Woodland & 20 & 4.85 & $(3.85 ; 5.85)$ & 10 & 3.30 & $(1.68 ; 4.92)$ & & \\
\hline & Disturbed & 63 & 1.29 & $(0.98 ; 1.59)$ & 24 & 0.38 & $(0.13 ; 0.62)$ & & \\
\hline \multirow[t]{3}{*}{ Deb } & Open & 95 & 1.22 & $(0.97 ; 1.47)$ & 42 & 0.67 & $(0.44 ; 0.89)$ & \multirow[t]{3}{*}{0.000} & \multirow[t]{3}{*}{0.165} \\
\hline & Woodland & 20 & 1.20 & $(0.58 ; 1.82)$ & 10 & 0.90 & $(0.37 ; 1.43)$ & & \\
\hline & Disturbed & 63 & 4.13 & $(3.52 ; 4.74)$ & 24 & 3.21 & $(2.44 ; 3.98)$ & & \\
\hline \multirow[t]{2}{*}{ Var } & Open & 95 & 4.33 & $(3.84 ; 4.81)$ & 42 & 3.55 & $(2.96 ; 4.14)$ & \multirow[t]{2}{*}{0.000} & \multirow[t]{2}{*}{0.460} \\
\hline & Woodland & 20 & 5.30 & $(4.31 ; 6.29)$ & 10 & 3.30 & $(1.99 ; 4.61)$ & & \\
\hline
\end{tabular}

$N$ number of samples, $95 \%$ CI confidence interval 
Fig. 6 Rarefaction curves (thick lines) with $95 \%$ confidence intervals (area between the slim lines) for number of all species (a), number of endemic species (b) and number of genera (c) in relation to two sampling methods-HCM (solid line) and PTM (dashed line)
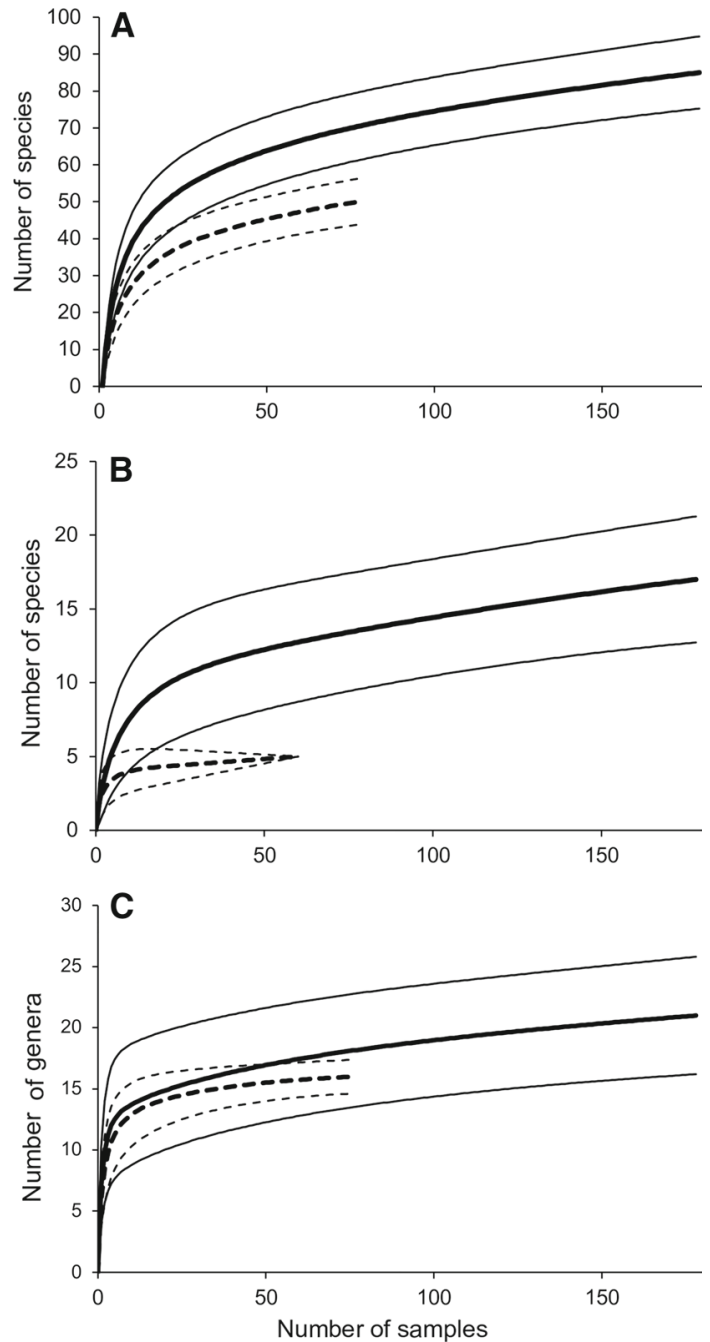

exclusively by HCM inhabit environments where pitfall traps cannot be used. In our opinion, these results point to the most significant disadvantages of PTM in estimating species diversity in the Mediterranean habitats.

HCM samples a broader spectrum of ant assemblages, including presence-absence of species, presence-absence of genera, and number of species belonging to a particular genus. Also, assemblages detected by PTM consisted mostly of similar sets. However, there are some specific assemblages detected by HCM or PTM exclusively. Our analyses show that HCM is slightly biased towards several taxa with specific life histories or environmental requirements, while PTM is mostly biased towards common taxa. Despite these biases, the application of HCM can identify combinations of ant species associated with various aspects of different habitats and reveals results more consistent with a real pattern of biodiversity (c.f. Leibold and Mikkelson 2002). 
Fig. 7 Performance of HCM and PTM in recognizing of functional composition of ant assemblages referred to nesting preferences in investigated habitat types: a open habitat-HCM: $\mathrm{n}=990$, PTM: $\mathrm{n}=338 ; \mathbf{b}$ woodland habitatHCM: $\mathrm{n}=232$, PTM: $\mathrm{n}=75$; c disturbed habitat-HCM: $\mathrm{n}=596$, PTM: $\mathrm{n}=162$. The white bars show the total species pool. The dark grey bars represent the proportions of ant species for functional groups based on the HCM, whereas the bright grey bars represent PTM method. $95 \%$ confidence intervals for the Bailey's test are shown. Bailey's test $\mathrm{P}$ values are also shown when significant: $* \mathrm{P}<0.05$

Fig. 8 Ordination biplot of the PCA analysis representing variation of functional diversity of ant assemblages based on presence-absence data recorded with the two sampling methods: HCM and PTM. Labels: FRic functional richness, FEve functional evenness, FDis functional dispersion, $\operatorname{Rao} Q$ Rao's quadratic entropy
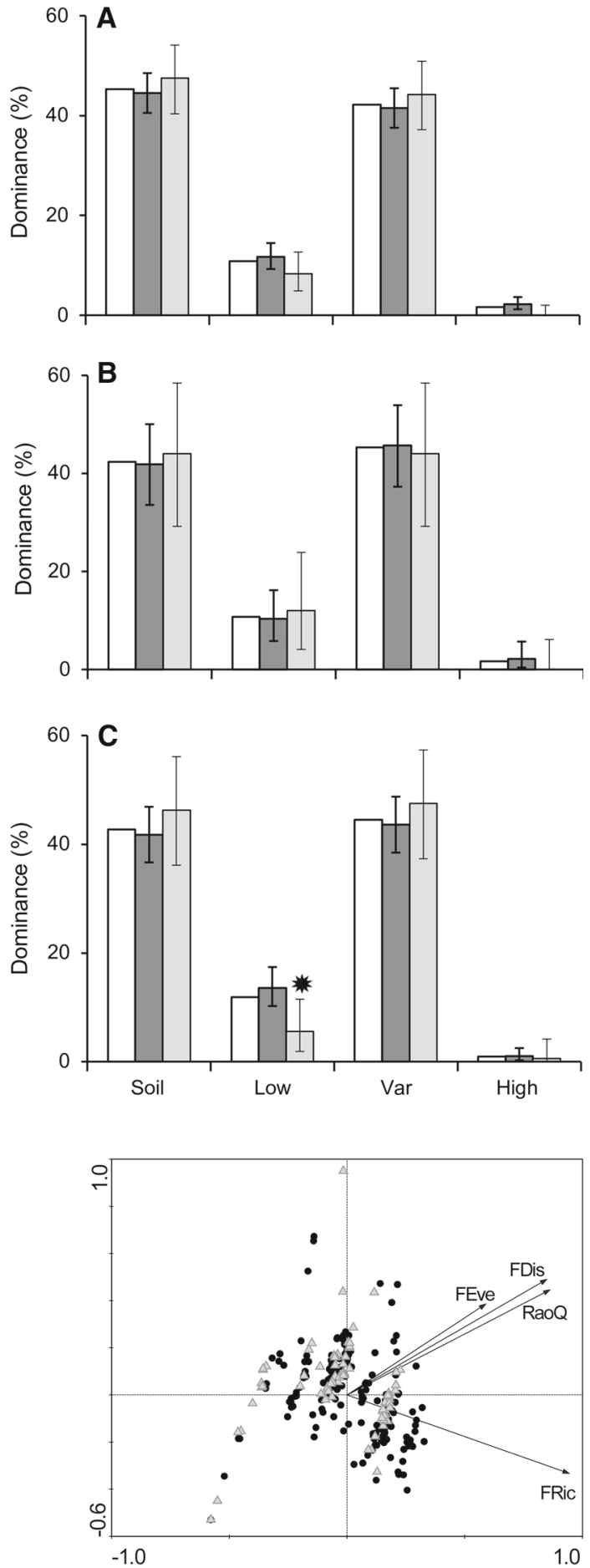
Both methods show no differences in detecting assemblage dispersion, i.e. distances of assemblages from the mean (centroid) for all samples belonging to a particular group. Despite the differences in spatial species turnover, both methods are equally effective in the detection of variation (multivariate dispersion) in combinations of taxa assemblages. Also, HCM and PTM produce the same results in studies of assemblage heterogeneity (variation) at a given set of environmental conditions. Both methods allow detecting whether investigated assemblages, at various habitat types, are more or less heterogeneous and whether the variation between assemblages decrease or increase along the environmental gradients.

\section{PTM and HCM in functional diversity assessment}

Despite the fact that the PTM detected a lower number of species for each functional group, both methods detect similar assemblages, and the performance of the sampling methods was the same, even when different habitat types were considered. We recorded one exception for disturbed habitats, where PTM underestimates species nesting in litter and on low vegetation. This suggests that disturbed habitats may require a higher sampling effort when PTM is used or that the method is generally less effective, especially for the aforementioned ant groups. Our results also suggest that a disturbed environment is susceptible to restriction or loss of functional redundancy, in which functions of certain species or groups of species are replaced by other species or assemblages (Rosenfeld 2002; McGuire and Treseder 2010). In Crete, this phenomenon can occur more often than in disturbed environments with originally poorer species assemblages. Considering the fact that under such conditions PTM and HCM can give different results, we recommend applying both methods in surveys performed in anthropogenic habitats, with increased sampling effort for PTM. Discussed results imply that the output of the filtering of an ant group, defined based on nesting preferences, is similar in both methods. That being said, our results confirmed that the PTM tends to collect larger taxa than HCM. Underestimating multivariate diversity of ant assemblages, i.e. functional richness (FRic) and functional dispersion (FDis), may lead to inaccurate conclusions in ecological studies on resource use, niche occupation, ecosystem services, biological invasions, and in proposing conservation strategies. Lower FRic shows that some of the potentially available resources are unused or that ecosystem services are poor. If the functional trait represents environmental tolerances, the lower FRic index implies the presence of gaps in the niche, which can be exploited by introduced species, resulting in a decrease in invasion resistance (see Tilman 1996, 2001; Dukes 2001; Mason et al. 2005). Lower FDis implies that detected species assemblages are functionally poor and consist of species of similar functional traits. If the true values of functional diversity indices are higher, conclusions based on underestimated findings can lead to improper conservation and restoration management. That is especially true in efforts attempting to reconstruct or conserve healthy and functioning ecosystems (c.f. Cadotte et al. 2011; Leclerc et al. 2020).

It is worth underlining that when a single functional characteristic was included in the analyses (nesting preferences, Weber's length, evolutionary origin), similar results for both HCM and PTM were found (with the exception of the slightly larger Webber's length found with PTM). When the functional analysis was based on multiple functional characteristics, results depended on the sampling method. The characteristic that is least dependent on the sampling method is functional evenness (FEve). Our results revealed that Rao's quadratic entropy (RaoQ) is redundant in relation to FDis, as it was previously 
suggested based on simulation data (Laliberté and Legendre 2010). The FDis index seems to be more capable of testing potential differences between various groups of interest, including direct testing, analogous to assemblage dispersion tests (Anderson 2006; Laliberté and Legendre 2010). Functional diversity indices and multiple-traits approach provide a useful tool for hypotheses testing concerning different factors, such as global changes, ecosystem services or anthropogenic pressures on biodiversity (Cadotte et al. 2011; Leclerc et al. 2020), and understanding the differences between the sampling methods is crucial to validate this conclusion.

\section{Advantages and disadvantages of PTM and HCM}

Our results highlighted the importance of biological collections in global biodiversity research, confirming and strengthening their considerable potential to contribute to a more profound understanding of species patterns in nature. PTM, as a very sensitive method on recording cryptic/nocturnal species (see above the case with Stenamma debile, Aphaenogaster kervillei and Lasius myops), significantly contributed to the Cretan ant richness. Moreover, valuable data on species assemblages and distribution on the island or changes through time, can be extracted in the future (see also Pyke and Ehrlich 2010 for a further discussion on this subject). However, both methods mentioned above have their particular advantages and disadvantages.

Pitfall traps can be used only in localities with well-developed soil or litter layer, and they detect only a particular group of ants (Romero and Jaffe 1989; Sheikh et al. 2018). This method seems to be insufficient in rocky, steep, or flooded areas and is not applicable in anthropogenic habitats (Gotelli et al. 2011; Wiezik et al. 2015). PTM requires also revisiting the same sampling area. Thus, it is time consuming, while time is most often limited during scientific sampling. The biggest advantage of this method is the fact that it is self- operating and it samples continuously a relatively high number of taxa (Work et al. 2002; Schlick-Steiner et al. 2006; Sheikh et al. 2018), which probably contributed to their popularity in ecological surveys (Gotelli et al. 2011; Sheikh et al. 2018). Sampling success, however, depends both on species behavior and on the size of pitfalls traps, which also defines differences in sampling rates for beetles and wolf spiders (Work et al. 2002). Pitfall trapping, in comparison to other methods, is rather suitable for species represented by large and heavy individuals (Mommertz et al. 1996; Lee and Guénard 2019).

$\mathrm{HCM}$, in turn, can be used in a broader range of habitats, and it enables collecting distinctive ant groups (Gotelli et al. 2011). Hand collecting, a core method used in HCM, is less laborious, time-consuming, and focuses on target insects (Abril and Gómez 2013). Unfortunately, its efficiency depends on the experience of the investigator, and it has to be standardized to provide reliable data (Gotelli et al. 2011; Abril and Gómez 2013; Wong and Guénard 2017). However, as sampling effort in hand collecting depends on the physical abilities and experience of the collector, its standardization among different investigators is difficult (Wong and Guénard 2017).

The results of this study underline that the outcome of taxonomic inventory or estimation of functional composition and diversity depends on selected sampling methods (Wiezik et al. 2015; Lee and Guénard 2019). In our opinion, relying on a single method can strongly bias obtained results (see Wiezik et al. 2015; Hanisch et al. 2018). Thus, we recommend using an integrated approach that includes several complementary methods suitable for the studied habitat, especially when a survey aims to assess $\alpha-, \beta-$, and $\gamma-$ diversity. 
Acknowledgements We are very thankful to Dr. Brian L. Fisher for his comments and suggestions to improve an earlier version of the manuscript as well as to three anonymous referees for reviewing and improving a previous version of this manuscript. The authors thank Dr. Gabriela P. Camacho for proofreading the manuscript. The authors wish also to thank the NHMC technician Mrs. Ljubica Kardaki for her kind assistance with the NHMC ant collection during the laboratory preparation of the specimens by the first of the authors.Open Access This article is licensed under a Creative Commons Attribution 4.0 International License, which permits use, sharing, adaptation, distribution and reproduction in any medium or format, as long as you give appropriate credit to the original author(s) and the source, provide a link to the Creative Commons licence, and indicate if changes were made. The images or other third party material in this article are included in the article's Creative Commons licence, unless indicated otherwise in a credit line to the material. If material is not included in the article's Creative Commons licence and your intended use is not permitted by statutory regulation or exceeds the permitted use, you will need to obtain permission directly from the copyright holder. To view a copy of this licence, visit http://creativecommons.org/licenses/by/4.0/.

\section{References}

Abril S, Gómez C (2013) Rapid assessment of ant assemblages in public pine forests of the central Iberian Peninsula. For Ecol Manage 29:79-84

Agosti D, Alonso L (2000) The ALL protocol. In: Agosti D, Majer JD, Alonso LE, Schultz T (eds) Ants standard methods for measuring and monitoring biodiversity. Smithsonian Institution Press, Washington, pp 204-206

Anderson MJ (2006) Distance-based tests for homogeneity of multivariate dispersions. Biometrics 62:245-253

Anderson MJ, Ellingsen KE, McArdle BH (2006) Multivariate dispersion as a measure of beta diversity. Ecol Lett 9:683-693

Bailey BJR (1980) Large sample simultaneous confidence intervals for the multinomial probabilities based on transformations of the cell frequencies. Technometrics 22:583-589

Borowiec L, Salata S (2014) Review of Mediterranean members of the Aphaenogaster cecconii group (Hymenoptera: Formicidae), with description of four new species. Zootaxa 3861(1):40-60

Bosmans R, Van Keer J, Russell-Smith A, Kronestedt T, Alderweireldt M, Bosselaers J, De Koninck H (2013) Spiders of Crete (Araneae). A catalogue of all currently known species from the Greek island of Crete. Nieuw Belgis Arachn V 28(1):1-147

Botta-Dukát Z (2005) Rao's quadratic entropy as a measure of functional diversity based on multiple traits. J Veg Sci 16:533-540

Cadotte MW, Carscadden K, Mirotchnick N (2011) Beyond species: functional diversity and the maintenance of ecological processes and services. J Appl Ecol 48:1079-1087

Chao A (1987) Estimating the population size for capture-recapture data with unequal catchability. Biometrics 43:783-791

Clarke KR (1993) Non-parametric multivariate analyses of changes in community structure. Aust J Ecol $18(1): 117-143$

Colwell R (2009) EstimateS: Statistical estimation of species richness and shared species from samples. Version 8.2. https://viceroy.eeb.uconn.edu/EstimateS

Colwell RK, Mao CX, Chang J (2004) Interpolating, extrapolating, and comparing incidence-based species accumulation curves. Ecology 85:2717-2727

Cuttelod A, García N, Malak DA, Temple HJ, Katariya V (2009) The Mediterranean: a biodiversity hotspot under threat. Wildlife in a Changing World-an analysis of the 2008 IUCN Red List of Threatened Species 89-101.

Dermitzakis M (1990) Paleogeography, geodynamic processes and event stratigraphy during the late Cenozoic of the Aegean Area. Atti dei Conveg Lincei 85:263-288

Di Castri F, Goodall DW, Spechi RL (1981) Mediterranean-type shrublands. Elsevier, Amsterdam

Donoso DA, Ramón G (2009) Composition of a high diversity leaf litter ant community (Hymenoptera: Formicidae) from an Ecuadorian pre-montane rainforest. Ann Soc Entomolo Fr 45:487-499

Douris V, Cameron R, Rodakis G, Lecanidou R (1998) Mitochondrial phylogeography of the land snail Albinaria in Crete: long-term geological and short-term vicariance effects. Evolution 52:116-125

Dukes JS (2001) Biodiversity and invasibility in grassland microcosms. Oecologia 126:563-568

Ellison AM, Record S, Arguello A, Gotelli NJ (2007) Rapid inventory of the ant assemblage in a temperate hardwood forest: species composition and assessment of sampling methods. Environ Entomol 36(4):766-775

Fassoulas C (2001) Field guide to the geology of Crete, 2nd edn. Natural History Museum of Crete, Heraklio, p 103 
Fisher BL (1999) Improving inventory efficiency: a case study of leaf-litter ant diversity in Madagascar. Ecol Appl 9:714-731

Gotelli NJ, Ellison AM, Dunn RR, Sanders NJ (2011) Counting ants (Hymenoptera: Formicidae): biodiversity sampling and statistical analysis for myrmecologists. Myrmecol N 15:13-19

Gower JC (1971) A general coefficient of similarity and some of its properties. Biometrics 27:857-871

Grove AT, Rackham O (1993) Threatened landscapes in the Mediterranean: examples from Crete. Landscape Urban Plan 24:279-292

Hammer $\check{R}$, Harper DAT, Ryan PD (2001) (PAST) Paleontological statistics software package for education and data analysis. Palaeontol Electron 4(1):9

Hanisch PE, Suarez AV, Tubaro PL, Paris CI (2018) Co-occurrence patterns in a subtropical ant community revealed by complementary sampling methodologies. Environ Entomol 47:1402-1412

Hausdorf B, Sauer J (2009) Revision of the Helicellinae of Crete (Gastropoda: Hygromiidae). Zool J Linnean Soc 157:373-419

Higgins RJ, Lindgren BS (2012) An evaluation of methods for sampling ants (Hymenoptera: Formicidae) in British Columbia, Canada. Can Entomol 144:491-507

Hölldobler B, Wilson EO (1990) The ants. Harvard University Press, Massachusetts, p 732

Jacquemin J, Roisin Y, Leponce M (2016) Spatio-temporal variation in ant (Hymenoptera: Formicidae) communities in leaf-litter and soil layers in a premontane tropical forest. Myrmec N 22:129-139

Kaltsas D, Simaiakis S (2012) Seasonal patterns of activity of Scolopendra cretica and S. cingulata (Chilopoda, Scolopendromorpha) in East Mediterranean maquis ecosystem. Intern J Myriapod 7:1-14

Kaltsas D, Trichas A, Kougioumoutzis K, Chatzaki M (2013) Ground beetles respond to grazing at assemblage level, rather than species-specifically: the case of Cretan shrublands. J Insect Conserv 17(4):681-697

Kindt R, Coe R (2005) Tree diversity analysis. A manual and software for common statistical methods for ecological and biodiversity studies. Nairobi World Agroforestry Centre (ICRAF), Nairobi

King JR, Porter SD (2005) Evaluation of sampling methods and species richness estimators for ants in upland ecosystems in Florida. Environ Entomol 34(6):1566-1578

Laliberté E, Legendre P (2010) A distance-based framework for measuring functional diversity from multiple traits. Ecology 91:299-305

Leclerc C, Villéger S, Marino C, Bellard C (2020) Global changes threaten functional and taxonomic diversity of insular species worldwide. Divers Distrib 26:402-414

Lee RH, Guénard B (2019) Choices of sampling method bias functional components estimation and ability to discriminate assembly mechanisms. Methods Ecol Evol 10:867-878

Legakis A, Kollaros D, Paragamian K, Trichas A, Voreadou C, Kypriotakis Z (1993) Ecological assessment of the coasts of Crete (Greece). Coastal Manage 21:143-154

Leibold MA, Mikkelson GM (2002) Coherence, species turnover, and boundary clumping: elements of meta-community structure. Oikos 97:237-250

Lepš J, Šmilauer P (2003) Multivariate analysis of ecological data using CANOCO. Cambridge University Press, New York

Lessard JP, Dunn RR, Parker CR, Sanders NJ (2007) Rarity and diversity in forest ant assemblages of Great Smoky Mountains National Park. Southeastern Nat 6(sp2):215-228

Longino JT, Branstetter MG, Ward PS (2019) Ant diversity patterns across tropical elevation gradients: effects of sampling method and subcommunity. Ecosphere 10(8):e02798

Lopes CT, Vasconcelos HL (2008) Evaluation of three methods for sampling ground-dwelling ants in the Brazilian Cerrado. Neotrop Entomol 37:399-405

Mason NW, Mouillot D, Lee WG, Wilson JB (2005) Functional richness, functional evenness and functional divergence: the primary components of functional diversity. Oikos 111(1):112-118

McGuire KL, Treseder KK (2010) Microbial communities and their relevance for ecosystem models: decomposition as a case study. Soil Biol Biochem 42:529-535

Mommertz S, Schauer C, Kösters N, Lang A, Filser J (1996) A comparison of D-Vac suction, fenced and unfenced pitfall trap sampling of epigeal arthropods in agro-ecosystems. Ann Zool Fenn 33:117-124

Pacheco R, Vasconcelos HL (2012) Subterranean pitfall traps: is it worth including them in your ant sampling protocol? Psyche 2012:1-9

Parr CL, Dunn RR, Sanders NJ, Weiser MD, Photakis M, Bishop TR, Fitzpatrick MC, Arnan X, Baccaro F, Brandão CR, Chick L (2017) GlobalAnts: a new database on the geography of ant traits (Hymenoptera: Formicidae). Insect Conserv Diver 10(1):5-20

Poulakakis N, Kapli P, Lymberakis P, Trichas A, Vardinoyiannis K, Sfenthourakis S, Mylonas M (2015) A review of phylogeographic analyses of animal taxa from the Aegean and surrounding regions. J Zool Syst Evol Res 53(1):18-32 
Pyke GH, Ehrlich PR (2010) Biological collections and ecological/environmental research: a review, some observations and a look to the future. Biol Rev 85:247-266

Rackham O, Moody J (1996) The making of the Cretan landscape. Manchester University Press, Manchester, $\mathrm{NH}$

Romero H, Jaffe K (1989) A comparison of methods for sampling ants (Hymenoptera, Formicidae) in savannas. Biotropica 21(4):348-352

Rosenfeld J (2002) Functional redundancy in ecology and conservation. Oikos 98(1):156-162

Salata S, Borowiec L (2015) A taxonomic revision of the genus Oxyopomyrmex André, 1881 (Hymenoptera: Formicidae). Zootaxa 4025(1):1-66

Salata S, Borowiec L (2017) Species of Tetramorium semilaeve complex from Balkans and Western Turkey, with description of two new species of (Hymenoptera: Formicidae: Myrmicinae). Ann Zool 67(2):279-313

Salata S, Borowiec L (2019) Preliminary contributions toward a revision of Greek Messor Forel, 1890 (Hymenoptera: Formicidae). Turk J Zool 43(1):52-67

Salata S, Borowiec L, Trichas A (2018) Taxonomic revision of the Cretan fauna of the genus Temnothorax Mayr, 1861 (Hymenoptera: Formicidae), with notes on the endemism of ant fauna of Crete. Ann Zool 68:769-808

Salata S, Borowiec L, Trichas A (2020) Review of ants (Hymenoptera: Formicidae) of Crete, with keys to species determination and zoogeographical remarks. Monogr Up Siles Mus 12:5-296

Sánchez-Bayo F, Wyckhuys KA (2019) Worldwide decline of the entomofauna: a review of its drivers. Biol Conserv 232:8-27

Schlick-Steiner BC, Steiner FM, Moder K, Bruckner A, Fiedler K, Christian E (2006) Assessing ant assemblages: pitfall trapping versus nest counting (Hymenoptera, Formicidae). Insec Soc 53(3):274-281

Schmalfuss S, Paragamian K, Sfenthourakis S (2004) The terrestrial isopods (Isopoda: Oniscidea) of Crete and the surrounding islands. Stuttg Beitr Natur Series A 662:1-74

Sfenthourakis S, Legakis A (2001) Hotspots of endemic terrestrial invertebrates in southern Greece. Biodivers Conserv 10(8):1387-1417

Sheikh AH, Ganaie GA, Thomas M, Bhandari R, Rather YA (2018) Ant pitfall trap sampling: an overview. J Entomol Res 42:421-436

Simaiakis S, Minelli A, Mylonas M (2004) The centipede fauna of Crete and its satellite islands. Isr J Zool 50:367-418

Soroye P, Newbold T, Kerr J (2020) Climate change contributes to widespread declines among bumble bees across continents. Science 367(6478):685-688

Spooner FE, Pearson RG, Freeman R (2018) Rapid warming is associated with population decline among terrestrial birds and mammals globally. Glob Change Biol 24:4521-4531

Tilman D (1996) Biodiversity: population versus ecosystem stability. Ecology 77:350-363

Tilman D (2001) Functional diversity. In: Levin SA (ed) Encyclopedia of biodiversity. Academic Press, London, pp 109-120

Trichas A, Lagkis A, Triantis K, Poulakakis N, Chatzaki M (2008) Biogeographic patterns of tenebrionid beetles (Coleoptera, Tenebrionidae) on four island groups in the south Aegean Sea. J Nat History 42(5):491-511

Tuanmu MN, Jetz W (2014) A global 1-km consensus land-cover product for biodiversity and ecosystem modelling. Glob Ecol Biogeogr 23:1031-1045

Triantis KA, Mylonas M (2009) Greek islands, biology. In: Gillespie RG, Clague DA (eds) Encyclopedia of islands. University of California Press, Berkeley, pp 388-392

Welter-Schultes F, Williams M (1999) History, island area and habitat availability determine land snail species richness of Aegean islands. J Biogeogr 26:239-249

Wiezik M, Svitok M, Wieziková A, Dovčiak M (2015) Identifying shifts in leaf-litter ant assemblages (Hymenoptera: Formicidae) across ecosystem boundaries using multiple sampling methods. PLoS ONE 10(7):e0134502

Wong KL, Guénard B (2017) Subterranean ants: summary and perspectives on field sampling methods, with notes on diversity and ecology (Hymenoptera: Formicidae). Myrmecol N 25:1-16

Work TT, Buddle CM, Korinus LM, Spence JR (2002) Pitfall trap size and capture of three taxa of litterdwelling arthropods: implications for biodiversity studies. Environ Entomol 31(3):438-448

Vellend M, Verheyen K, Flinn KM, Jacquemyn H, Kolb A, Van Calster H, Peterken G, Graae BJ, Bellemare J, Honnay O, Brunet J, Wulf M, Gerhadt F, Hermy M (2007) Homogenization of forest plant communities and weakening of species-environment relationships via agricultural land use. $\mathrm{J}$ Ecol 95:565-573 
Villéger SN, Mason WH, Mouillot D (2008) New multidimensional functional diversity indices for a multifaceted framework in functional ecology. Ecology 89:2290-2301

Vogiatzakis IN, Mannion AM, Sarris D (2016) Mediterranean island biodiversity and climate change: the last 10,000 years and the future. Biodiver Conserv 25(13):2597-2627

Publisher's Note Springer Nature remains neutral with regard to jurisdictional claims in published maps and institutional affiliations.

\section{Affiliations}

\section{Sebastian Salata ${ }^{1,2,3}$ (D) Konrad Kalarus $^{2}$ (1) - Lech Borowiec ${ }^{3}$ (1) $\cdot$ Apostolos Trichas $^{4}$ (D) $\cdot$ Krzysztof Kujawa $^{2}$}

1 Department of Entomology, California Academy of Sciences, San Francisco, CA 94118, USA

2 Department of Landscape Ecology, Institute for Agricultural and Forest Environment, Polish Academy of Sciences, Bukowska 19, 60-809 Poznan, Poland

3 Department of Biodiversity and Evolutionary Taxonomy, University of Wrocław, Przybyszewskiego 65, 51-148 Wrocław, Poland

4 University of Crete, Natural History Museum of Crete, GR-70013 Vasilika Vouton, Heraklion, Crete, Greece 